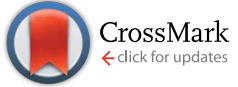

Cite this: RSC Adv., 2014, 4, 55077

Received 9th July 2014

Accepted 20th October 2014

DOI: $10.1039 / c 4 r a 06901 c$

www.rsc.org/advances

\section{Room temperature ionic liquids in a heat treatment process for metals $\uparrow$}

\author{
C. Schmidt, ${ }^{a}$ M. Beck, ${ }^{b}$ M. Ahrenberg, ${ }^{c}$ C. Schick, ${ }^{c}$ O. Keßler ${ }^{\mathrm{b}}$ and U. Kragl ${ }^{\star a}$ \\ Ionic liquids were found to be useful media for quenching of aluminum and steel alloys. In mixtures \\ containing up to $10 \% \mathrm{w} / \mathrm{w}$ water or ethanol they prevent film boiling (Leidenfrost effect) and result in \\ very high and constant cooling rates. The ionic liquids $[\mathrm{EMIm}]\left[\mathrm{NTf}_{2}\right],[\mathrm{EMIm}]\left[\mathrm{EtSO}_{4}\right]$ and Ammoeng®110 \\ exhibit remarkable stability when metals at temperatures well above the ionic liquid decomposition \\ temperature were quenched.
}

\section{Introduction}

Ionic liquids (ILs) have been tested for a wide range of applications. In some cases they have been used to substitute volatile solvents in organic synthesis and nanomaterial processing. ${ }^{1}$ However, in the last few years the focus of research is shifting towards their application as functional materials. Due to a variety of available anions and cations, ILs can be specifically tuned and designed for manifold applications. Both, the extremely low vapor pressure, and their tribological and thermal properties, as well as their extremely robust nature, have led to novel applications in addition to the usage as electrolytes in batteries and capacitors. They are already employed as lubricant in pump systems or as liquid piston in gas liquefaction processes..$^{2-5}$ Consequently, a number of ionic liquids are now available in large quantities at a reasonable cost.

In the heat treatment of metallic alloys large amounts of a quenching medium are usually necessary to achieve sufficient cooling capacity and cooling rates, which determine mechanical properties such as hardness and microstructure. Moreover, the cooling has to be gentle and uniform in order to avoid strong temperature gradients in the metal, leading to distortion and residual stresses. ${ }^{6}$

For cooling of hot metals, water is commonly used as evaporating quenching liquid. A major problem associated with its use is the formation of an insulating vapor film on the surface of the component, which decreases the rate of the heat transfer. This particular effect is the so called Leidenfrost-phenomenon. During the quenching process the vapor film breaks

${ }^{a}$ Institute of Chemistry, University of Rostock, Albert-Einstein-Str. 3a, 18059 Rostock, Germany. E-mail: udo.kragl@uni-rostock.de

${ }^{b}$ Chair of Materials Science, University of Rostock, Albert-Einstein-Str. 2, 18059 Rostock, Germany

'Institute of Physics, University of Rostock, Wismarsche Str. 43-45, 18051 Rostock, Germany

$\dagger$ Electronic supplementary information (ESI) available. See DOI: 10.1039/c4ra06901c sporadically, leading to increased local heat transfer and therefore to distortions and local stress within the structure of the metal. The component distortion can be overcome by oversizing the part and intensive reworking to obtain the desired dimensions. If these costly and time-consuming mechanical post-processing steps can be reduced, a part of the payoff can be used to cover the higher costs of a quenching medium with better properties.

In recent years various methods to circumvent the negative effects of quenching with evaporating liquids have been developed. One of these methods involves polymer additives in aqueous baths which deposit as a thin film on the metal pieces, which can adversely affect the film boiling on the component surface. Another alternative is gas quenching, which is carried out under nitrogen or helium atmosphere at pressures up to 1020 bar. The advantage is a more uniform quench, but the costs are significantly higher and the quenching power is lower. Also baths containing salt or metal melts are used.,

None of the quenching media developed so far fulfills all requirements such as thermal stability, low vapor pressure, quenching rate, uniformity and simplicity in handling, to be the ideal quenching medium. However, we have recently demonstrated that ILs come quite close to these specifications. ${ }^{9}$ Due to low melting points, in many cases below room temperature, and their extremely low vapor pressure, as well as high stability towards short-term temperature stress, ILs can be considered as promising candidates for quenching media. In contrast to immersion baths containing salt or metal melts, ionic liquids can be employed at room temperature.

First results on the use of ILs containing up to $10 \% \mathrm{w} / \mathrm{w}$ for quenching of an aluminum alloy have shown remarkable properties of the cooling medium such as high quenching power at elevated temperatures and homogenous cooling. ${ }^{9}$ Herein we present an expansion of the previously reported method to the quenching of steel at temperatures up to $850{ }^{\circ} \mathrm{C}$, and the use of other volatile additives to increase the quenching process. We report on the influence of the quenching process 
on the properties and the chemical composition of the ionic liquids.

\section{Experimental}

The experimental setup consists of a muffle furnace (type MLW) for sample heating. The immersion quenching tanks vary in shape and dimension and are made of glass or stainless steel. These tanks are filled with about $900 \mathrm{~mL}$ of IL or 15 and $35 \mathrm{~L}$ water, respectively. The smallest vessel is heated with the hot plate of a magnetic stirrer. A guide rail is mounted above the quenching bath for the proper placement of the hot metal sample. As samples metal cylinders (length: $120 \mathrm{~mm}$, diameter: $29.5 \mathrm{~mm})$ or plates $(45 \times 80 \times 8 \mathrm{~mm})$ were used. Various aluminum alloys (EN AW-2219, EN AW-6082, EN AW-7349) and steels (C45 and X5CrNi-18-10) were tested. Most of the tests were recorded with a video camera (Canon EOS 60D). The temperature was measured with a mobile measurement system (Data Acquisition System, National Instruments) comprising at least 5 thermocouples and a temperature slave (GE - National Experiments/LabView 2011 Signal Express). The cooling curves of the sample were recorded with a sampling frequency of 50 Hz. The curves were smoothed with a moving average over 10 points. The cooling rates were calculated as the first order derivative of the cooling curves. The bath temperature was detected by three type $\mathrm{K}$ thermocouples $(\varnothing 1.0 \mathrm{~mm})$ in different positions. The final bath temperature for steels was about $143{ }^{\circ} \mathrm{C}$ and for aluminum alloys about $80{ }^{\circ} \mathrm{C}$. No additional cooling was applied during the quenching experiments.

\section{Analysis and spectroscopic measurements}

${ }^{1} \mathrm{H}-,{ }^{19} \mathrm{~F}-,{ }^{13} \mathrm{C}$ - and DEPT-NMR spectra were recorded with a Bruker ARX 300 spectrometer. The spectra were calibrated with respect to traces of DMSO or $\mathrm{H}_{2} \mathrm{O}$ in the corresponding deuterated solvent $\left(\mathrm{d}_{6}\right.$-DMSO: ${ }^{1} \mathrm{H} \delta=2.50 ;{ }^{13} \mathrm{C} \delta=39.5 \mathrm{ppm}$; $\left.\mathrm{D}_{2} \mathrm{O}:{ }^{1} \mathrm{H} \delta=3.32 \mathrm{ppm}\right)$. MIR spectra $\left(500-4000 \mathrm{~cm}^{-1}\right)$ were recorded using the ATR technique with a Thermo Nicolet 380 FT-IR spectrometer. Elemental analyses for C, H, N, and S were obtained with a Flash EA 1112 NC Analyser from CE Instruments (experimental error $\pm 0.5 \%$ ). UV/Vis spectra were recorded with a Perkin-Elmer Lambda 2 spectrometer using quartz cuvettes (Suprasil ${ }^{\circledR}, d=10 \mathrm{~mm}$ ). Mass spectra were recorded in the electron ionization mode with a Finnigan MAT 95-XP (Thermo Electron). For electrospray ionisation experiments, the HPLC system was coupled to a 6210 Time-of-Flight LC/MS (Agilent) with an eluent composition of $\mathrm{MeOH} / 0.1 \% \mathrm{HCOOH}$ in water $90: 10$.

Melting $T_{\mathrm{m}}$ and decomposition $T_{\mathrm{d}}$ temperatures were determined by DSC or TGA measurements using a Mettler Toledo DSC823e and a Setaram Labsys ${ }^{\mathrm{TM}}$ - TGA in the range of $30-1600{ }^{\circ} \mathrm{C}$ with a heating rate of $10 \mathrm{~K} \mathrm{~min}^{-1}\left(\mathrm{~N}_{2}\right.$ atmosphere, $\mathrm{Pt}$ crucible). The melting points are given as peak temperatures, whereas decomposition temperatures were determined at the onset of the peak. The moisture content of the ionic liquids was measured by KF Karl-Fischer-titration using a 756/831 KFCoulometer from Metrohm. The viscosities of the ILs were determined using a Stabinger Viscometer SVM 3000 for dynamic viscosity with the M5-Single-point-method.

\section{Materials}

Ionic liquids, [EMIm][ $\left.\mathrm{NTf}_{2}\right]$ (1-ethyl-3-methylimidazolium bis(trifluoromethylsulfonyl)imid, $T_{\mathrm{d}}=471{ }^{\circ} \mathrm{C},{ }^{10}$ IoLiTec, $\geq 98 \%$ ), [EMIm] $\left[\mathrm{EtSO}_{4}\right]$ (1-ethyl-3-methylimidazolium ethylsulfate), $T_{\mathrm{d}}=$ $365{ }^{\circ} \mathrm{C},{ }^{11}$ BASF Germany, $\geq 98 \%$, Ammoeng ${ }^{\circledR} 110, T_{\mathrm{d}}=374{ }^{\circ} \mathrm{C}$, (Solvent Innovation/Merck, $\geq 95 \%$ ) after evaporation of isopropanol), ethanol (Fluka, $\geq 98 \%$ ) and quenching oil ISOMAX®166 (Petrofer) were used as received without any further purification.

The aluminum alloys EN AW-2219, EN AW-6082, EN AW7049, C45, X5CrNi-18-10 were machined into the required dimensions and cleaned with deionized water and ethanol prior to the quenching experiments. The metal samples were heated up to the recommended annealing temperatures (for EN AW$6082 T=540{ }^{\circ} \mathrm{C}$; for EN AW-2219 $T=535{ }^{\circ} \mathrm{C}$; for EN AW-7349 $T=470{ }^{\circ} \mathrm{C}$; for $\mathrm{C} 45 \& \mathrm{X} 5 \mathrm{CrNi}-18-10 \mathrm{~T}=850{ }^{\circ} \mathrm{C}$ ) under ambient atmosphere. When the samples achieved the desired temperature, they were removed from the furnace and inserted immediately into the quenching bath. During the short transfer time between furnace and bath of about 10 seconds, the samples cooled down for a maximum of $10-20 \mathrm{~K}$. The IL is preheated to a constant temperature of $30{ }^{\circ} \mathrm{C}$ and cooled down after the quench with a thermostat. For comparison, quenching oil experiments were also performed with a bath temperature of $85{ }^{\circ} \mathrm{C}$. Deionized water or ethanol (Fluka, $\geq 98 \%$ ) were tested as additives.

After each quenching process the metal-samples were cleaned by immersion in deionized water and rinsed with ethanol. Samples of the respective IL were taken before and after each experiment from the quenching bath for chemical analysis.

Due to the high immersion temperatures especially of the steel, the bath was investigated for possible decomposition products in the liquid phase by IR, NMR, UV/Vis, ESI- and EImass spectroscopy and elemental analysis. The exact decomposition temperatures were previously determined by TGA and are in accordance with the literature data. ${ }^{\mathbf{1 0 , 1 1}}$ These temperatures are well below the immersion temperature of the aluminum and steel components, but it has to be considered, that the high temperature load occurs only very shortly.

\section{Results \& discussion}

\section{Aluminum quenching}

In previous experiments we demonstrated that the aluminum alloy EN AW-6082 with a solution annealing temperature of $540{ }^{\circ} \mathrm{C}$ can be successfully quenched in [EMIm] [NTf $\left.\mathrm{NT}_{2}\right]$ and $[\mathrm{EMIm}]\left[\mathrm{EtSO}_{4}\right] .{ }^{9}$ By addition of up to $5 \% \mathrm{w} / \mathrm{w}$ of water very high cooling rates can be achieved while film boiling is almost completely suppressed. With these promising results in hand, we were interested in expanding the scope of this new quenching method. Due to its high technical and economic significance, we selected steel as a further subject for our 
studies. Steel products such as $\mathrm{C} 45$ and $\mathrm{X} 5 \mathrm{CrNi}$ 18-10 require higher immersion temperatures than the previously examined aluminum alloys (about $850{ }^{\circ} \mathrm{C}$ ).

The ionic liquids used were selected for different reasons (Fig. 1). [EMIm] $\left[\mathrm{NTf}_{2}\right]$ is known for its high thermal stability and low vapor pressure. ${ }^{\mathbf{1 3}}$ Compared to $[\mathrm{EMIm}]\left[\mathrm{EtSO}_{4}\right]$ it is rather expensive and is provided only by a few suppliers in small quantities. In contrast, $[\mathrm{EMIm}]\left[\mathrm{EtSO}_{4}\right]$ is already produced on the industrial scale and available at reasonable cost, enabling to perform large scale experiments. As a reference, tap water and the quenching-oil ISOMAX®166 were used as quenching medium. Ammoeng ${ }^{\circledR} 110$ was selected to provide a comparison to typical quenching oils such as the ISOMAX®166 (a blend of polymers). Notably, ISOMAX®166 and Ammoeng ${ }^{\circledR 110}$ have similar viscosities. In accordance with industrial processes involving quenching oils, the bath was heated prior to immersion of the sample $\left(T=85^{\circ} \mathrm{C}\right)$ in order to reduce the viscosity of the oil. Under these conditions, the oil and [EMIm] $\left.\mathrm{NTf}_{2}\right]$ exhibit similar cooling curves as shown in Fig. 2. The graph shows the temperature of the alloy sample in its surface near region. It should be noted that $3.5 \% \mathrm{w} / \mathrm{w}$ of water was added to the IL in order to increase the cooling rate. ${ }^{9}$ The rapid drop of the temperature within the first seconds indicates a very good heat transfer. For water there is only a slight decrease of the temperature for almost ten seconds, which is due to film boiling. When the film is breaking up after 12 seconds the heat a)

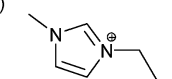

b)

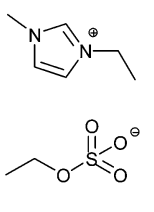

c)

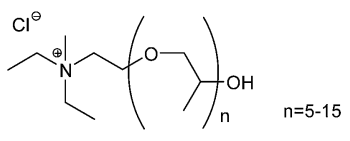

Fig. 1 Structures of the studied ILs; (a) [EMIm] $\left[\mathrm{NTf}_{2}\right]$ (b) $[\mathrm{EMIm}]\left[\mathrm{EtSO}_{4}\right]$; (c) Ammoeng ${ }^{\circledR} 110$.

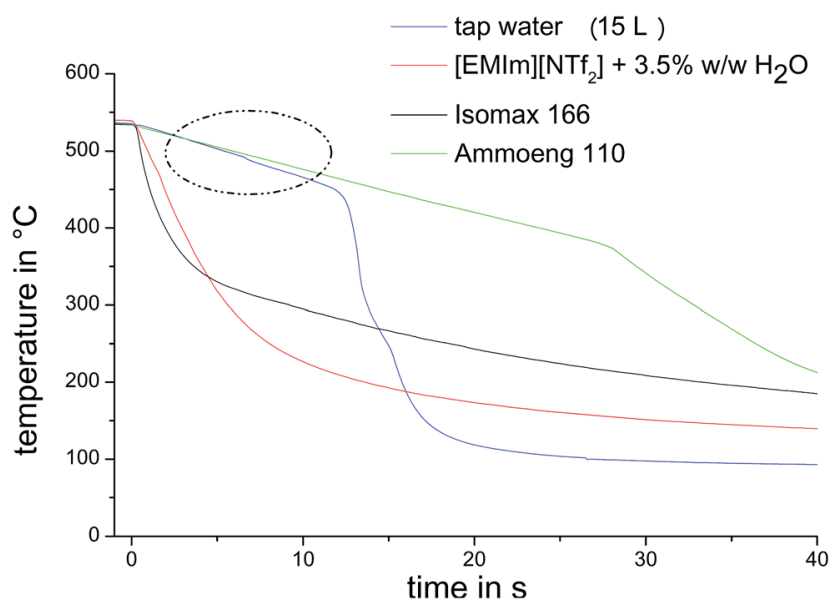

Fig. 2 Cooling curve of aluminum alloy EN AW-6082 in Ammoeng ${ }^{\circledR} 110$, ISOMAX 166, tap water and [EMIm] [NTf $\left.{ }_{2}\right]$ with $3.5 \% \mathrm{w} /$ w $\mathrm{H}_{2} \mathrm{O}$ with an initial bath temperature of $85^{\circ} \mathrm{C}$ and a volume of $0.9 \mathrm{~L}$; the region of film boiling in water is highlighted. transfer increases drastically. Due to the heat loss by evaporation of water, the final temperature of the IL bath is somewhat lower than the one of the oil bath (not shown). For Ammoeng®110 the same final temperature was found. However, at the beginning a film boiling with a smaller cooling rate was observed (see Fig. 2, green line). Compared to water, the film boiling period is significantly extended and cannot be reduced by lowering the initial bath temperature.

This also occurs in absence of water and can be explained by the formation of volatile decomposition products. Therefore we conclude that Ammoeng ${ }^{\circledR 110}$ is not suitable as a cooling liquid in spite of the similarity of the physicochemical properties to the industrial quenching oil ISOMAX®166.

Fig. 3 shows the quenching effect of $[\mathrm{EMIm}]\left[\mathrm{EtSO}_{4}\right]$ for the aluminum alloy EN AW-6082 at an initial bath temperature of $30{ }^{\circ} \mathrm{C}$. Based on the temperature-time profile and the cooling rate it can be concluded that the pure ionic liquids exhibit no macroscopic film boiling. Regarding the immersion temperature of the samples, this result is rather unexpected. These temperatures are well above the decomposition temperatures of the ionic liquids of $471{ }^{\circ} \mathrm{C}$ for [EMIm] $\left[\mathrm{NTf}_{2}\right]$ and $365{ }^{\circ} \mathrm{C}$ for [EMIm] $\left[\right.$ EtSO $\left._{4}\right] \cdot{ }^{10,11,14}$ However, such high heat loads occur only for relatively short periods.

The cooling effect can be greatly enhanced by addition of small amounts of water or ethanol. The rapid evaporation of the volatile solvent drastically reduces the thermal stress of the ionic liquid. There is no significant difference between the quenching effect of $5 \% \mathrm{w} / \mathrm{w}$ water or $10 \% \mathrm{w} / \mathrm{w}$ ethanol in the ionic liquid $[\mathrm{EMIm}]\left[\mathrm{EtSO}_{4}\right]$. However, film boiling sets in at ethanol concentrations of $20 \% \mathrm{w} / \mathrm{w}$. This is indicated by the lower slope of the curve during the first seconds. The change in the heat capacity of the quenching medium due to the different mixtures is of less importance than the effect of the vaporization of the volatile part. This vaporization cooling makes use of the vaporization enthalpy, but benefits even more from the intensive mixing by the formed gas bubbles which even disturb the stagnant layer on the alloys surface.

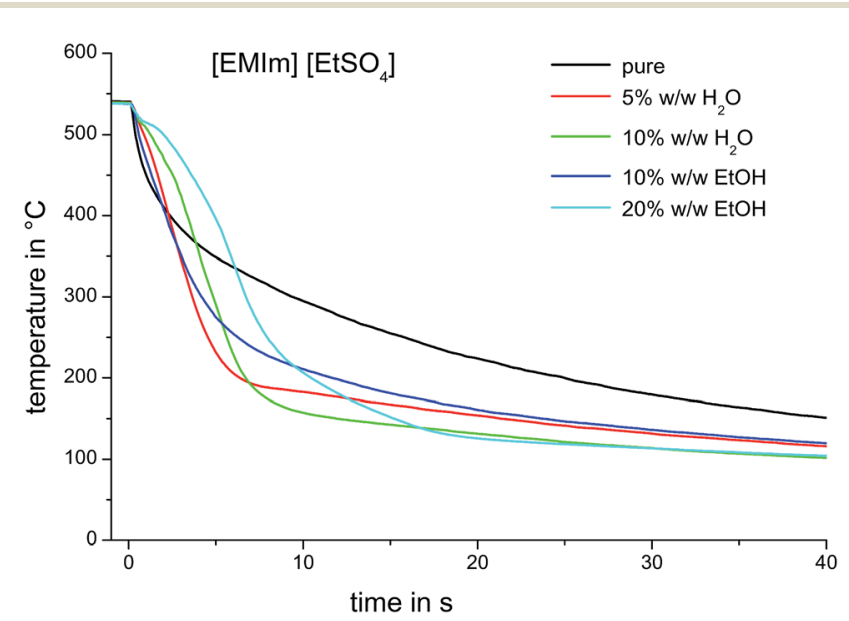

Fig. 3 Influence of the additive concentration on the quenching profile of aluminum alloy EN AW-6082 at $30{ }^{\circ} \mathrm{C}$ with $[\mathrm{EMIm}]\left[\mathrm{EtSO}{ }_{4}\right]$. 
From the visual observation of the quenching process it is obvious that increasing additive content results in a more intensive nucleation boiling stage, but not yet in a closed vapor film. A similar behavior is observed for [EMIm] $\left.\mathrm{NTf}_{2}\right]$, where film boiling is observed at an additive content $10 \% \mathrm{w} / \mathrm{w}$ ethanol, but not for the same amount of water. (see Fig. SI-1†).

\section{Steel quenching}

In metal processing the vast majority of alloys which undergo quenching are steels, which exhibit much higher annealing temperatures than other alloys (typically between $800{ }^{\circ} \mathrm{C}$ and $900^{\circ} \mathrm{C}$ ). In this case, initial tests showed that quenching in ionic liquids is possible as well. Fig. 4 shows the comparison of the quenching effect of steel in tap water and the two ionic liquids with an initial bath temperature of $30{ }^{\circ} \mathrm{C}$. For water the film boiling is clearly visible for an initial period of $2.5 \mathrm{~s}$. For the ionic liquids some bubbles are formed indicating either vaporization of remaining water traces, degassing of dissolved air or the formation of gaseous decomposition products. ${ }^{12}$ However, no macroscopically closed vapor film is formed. The bubble formation is more pronounced for [EMIm] $\left[\mathrm{EtSO}_{4}\right]$ than for $[\mathrm{EMIm}]\left[\mathrm{NTf}_{2}\right]$. The experiments with water were performed in a tank with a volume of $35 \mathrm{~L}$, whereas for the ionic liquids only $0.9 \mathrm{~L}$ were used. This is the reason why with increasing time the temperature for the water curve drops faster. For the IL the sample temperature drops below $400{ }^{\circ} \mathrm{C}$ after 20 seconds.

Pure $[\mathrm{EMIm}]\left[\mathrm{NTf}_{2}\right]$ exhibits a slightly higher cooling rate than [EMIm] $\left[\mathrm{EtSO}_{4}\right]$ (Fig. 5). Although the molar heat capacities of the two ionic liquids are slightly different, the volumetric heat capacity is almost identical in the range of $2.0 \mathrm{~J} \mathrm{~K}^{-1} \mathrm{~cm}^{-3} \cdot{ }^{13}$

Therefore, the different time profile might be caused by the decomposition of $[\mathrm{EMIm}]\left[\mathrm{EtSO}_{4}\right]$ and the resulting gas evolution, leading to local film formation and therefore reduced cooling rates. This behavior is similar to the observed effects at higher additive concentrations as discussed before (Fig. 3).

After quenching of steel samples with [EMIm] $\left[\mathrm{NTf}_{2}\right]$, a light brown coloration was observed. [EMIm] $\left[\mathrm{EtSO}_{4}\right]$ turns dark brown and volatile decomposition products are formed which

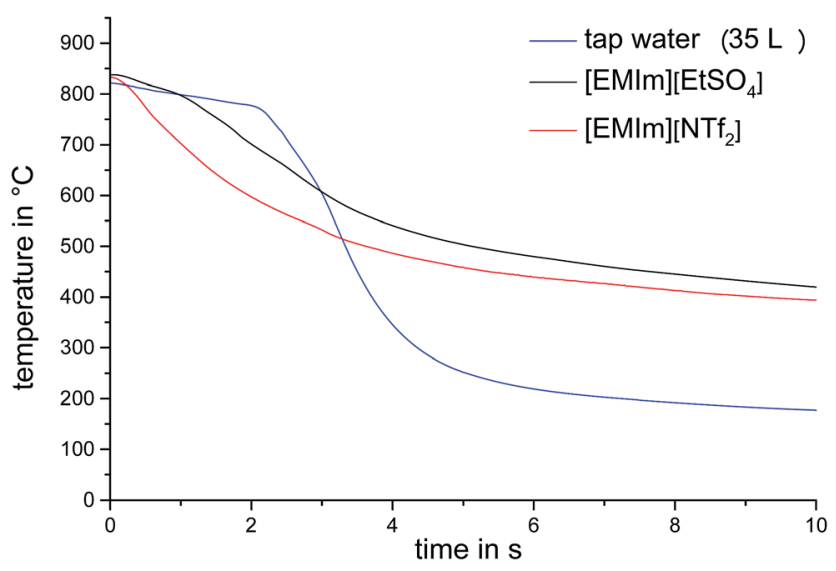

Fig. 4 Quenching curve of steel $X 5 \mathrm{CrNi} 18-10$ at $30^{\circ} \mathrm{C}$ with tap water, $[\mathrm{EMIm}]\left[\mathrm{EtSO}_{4}\right]$ and $[\mathrm{EMIm}]\left[\mathrm{NTf}_{2}\right] .900 \mathrm{~mL}$ of the ILs were used.

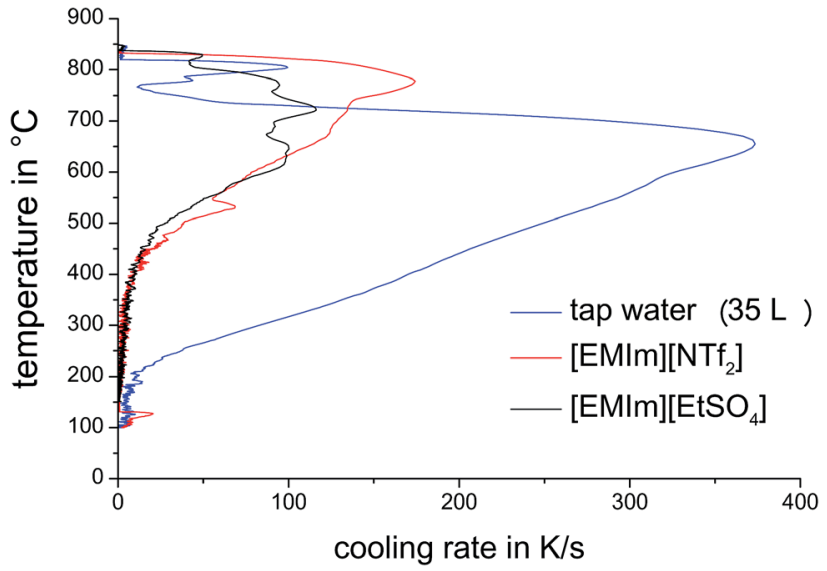

Fig. 5 Cooling rates of steel $X 5 \mathrm{CrNi} 18-10$ at $30{ }^{\circ} \mathrm{C}$ with tap water, $[\mathrm{EMIm}]\left[\mathrm{EtSO}_{4}\right]$ and $[\mathrm{EMIm}]\left[\mathrm{NTf}_{2}\right]$.

start to burn after immersion of the steel sample for about $20 \mathrm{~s}$. However, this is also the case for industrially used quenching oils in large-scale applications. The flames extinguish after consumption of the flammable vapors. In addition, an inert gas atmosphere as $\mathrm{CO}_{2}$ may be used to prevent ignition. According to the material safety data sheets, the flash points are $>200{ }^{\circ} \mathrm{C}$ for $[\mathrm{EMIm}]\left[\mathrm{NTf}_{2}\right]$ and $157{ }^{\circ} \mathrm{C}$ for $[\mathrm{EMIm}]\left[\mathrm{EtSO}_{4}\right]$. These values are exceeded by far with the immersion temperature of the aluminum alloys. However, we did not encounter any ignition of the vapor phase or aerosols formed during aluminum quenching, not even when EtOH was used.

Despite the dark coloring caused by the quenching of steel, no decomposition products could be detected in the liquid phases of ionic liquids with standard techniques such as NMR, IR UV/Vis, ESI-/EI-MS and elemental analysis within the given detection limits. Furthermore, no changes in the thermal behavior were observed. The IL's can be used repeatedly without loss of performance (see Fig. SI- $2 \dagger$ ).

The ethylsulfate combusts to a similar extend as the industrial quenching oil Isomax 166. Apparently, the decomposition products are gaseous and do therefore not contaminate the IL.

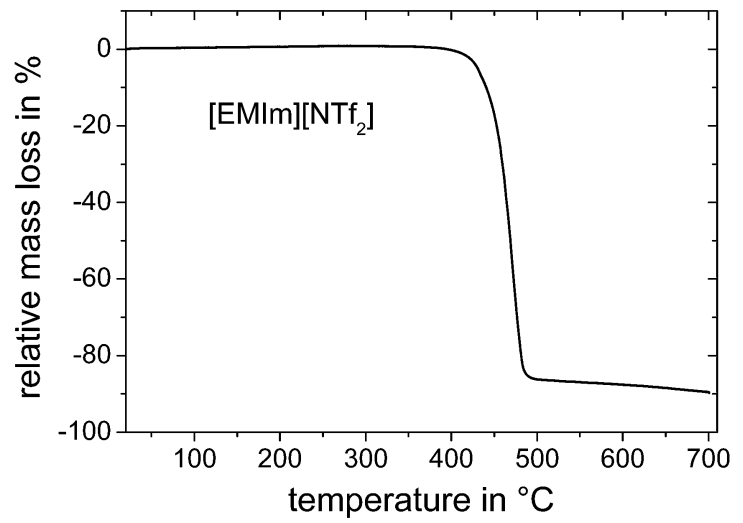

Fig. 6 Thermogravimetric analysis of [EMIm] $\left[\mathrm{NTf}_{2}\right]$ with a decomposition temperature of $448{ }^{\circ} \mathrm{C}$, heating rate $10 \mathrm{~K} \mathrm{~min}^{-1}$. 
Examination of the aerosols with acid base indicator paper we could not detect any basic or acidic decomposition products. Further work is in progress for monitoring the vapor phase directly above the hot metallic sample after immersion. Evaporating decomposition products are no problem for the quenching process itself, as long as the quenching curves and the cooling rates are not affected.

Our thermogravimetric examination of [EMIm] $\left[\mathrm{NTf}_{2}\right]$ yielded a decomposition temperature of $448{ }^{\circ} \mathrm{C}$ at a heating rate of $10 \mathrm{~K}$ $\min ^{-1}$, a value that is somewhat higher than the one reported in literature (Fig. 6). ${ }^{\mathbf{1 0}}$

According to the time profiles in Fig. 4, the ionic liquid is exposed to temperatures above the decomposition point for nearly 6 seconds. For analysis of the decomposition products, the ionic liquids were treated as follows: 42 quenches were performed for the aluminum alloy EN AW-6082 and ten quenches for the steel $\mathrm{X} 5 \mathrm{CrNi}-1810$. Subsequently, the ionic liquids were heated under ambient conditions to $550{ }^{\circ} \mathrm{C}$ for 30 minutes. Modern NMR techniques detect impurities well below $1 \% .^{15}$ The spectra clearly show a decreasing water content in accordance with data obtained from KF titration (1300 ppm for the fresh IL and 600 ppm after quenching, see ESI, Fig. SI-3 and Si-4†) Therefore, we conclude that non-volatile decomposition products are formed only in concentrations below the detection limit.

\section{Conclusions \& outlook}

We demonstrated that ILs as novel functional material exhibit excellent properties as quenching medium for metal alloys. ILs can easily withstand the immersion of parts with a temperature of $850{ }^{\circ} \mathrm{C}$ under negligible formation of non-volatile decomposition products. This result is in agreement with the fact that the decomposition temperature is a function of the heating rate. ${ }^{16}$ Furthermore we found that upon addition of volatile solvents such as ethanol or water the cooling rate can be further improved. Therefore, ionic liquids are coming close to the ideal quenching medium. They may offer the possibility to avoid post processing steps in the component manufacturing chain without using expensive cooling methods. Further investigation is under way to identify volatile decomposition products and to characterize the treated metal samples.

\section{Acknowledgements}

This work was supported by the DFG project: "Ionic liquids as quenching media for the heat treatment of metallic materials" KR 2491/8-1. The authors are grateful to Dr Robert Francke (Rostock University, Institute of Chemistry) for careful proofreading of the manuscript.

\section{Notes and references}

1 M. M. Jaworska, T. Kozlecki and A. Gorak, J. Polym. Eng., 2012, 32, 67-69.

2 R. Leo, A. C. Marschilok, K. J. Takeuchi and E. S. Takeuchi, Electrochim. Acta, 2013, 109, 27-32.

3 X. Zhao, S. Ren, M. Burns and M. Fichtner, J. Power Sources, 2014, 245, 706-711.

4 C. Dalmolin, S. R. Biaggio, N. Bocchi and R. C. Rocha-Filho, Mater. Chem. Phys., 2014, 147, 99-104.

5 Y. J. Kim, S. Kim, Y. K. Joshi, A. G. Fedorov and P. A. Kohl, Energy, 2012, 44, 1005-1016.

6 Handbook of Metallurgical Process Design, ed. G. E. Totten and K. Funatani, L. Xie, CRC Press, 2004.

7 F. Cosentino, N. Warnken, J.-C. Gebelin and R. C. Reed, J. Mater. Process. Technol., 2013, 213, 2350-2360.

8 B. Liscic, M. M. Tensi, L. C. F. Canale and G. E. Totten, Quenching Theory and Technology, Taylor and Francis Group, LLC, 2nd edn, 2010.

9 M. Beck, C. Schmidt, M. Ahrenberg, C. Schick, U. Kragl and O. Keßler, HTM, J. Heat Treat. Mater., 2013, 68, 214-223.

10 A. Noda, K. Hayamizu and M. Watanabe, J. Phys. Chem. B, 2001, 105, 4603-4610.

11 U. Domanska and M. Laskowska, J. Solution Chem., 2008, 37, 1271-1287.

12 D. Amariei, L. Courthéoux, S. Rossignol and C. Kappenstein, Chem. Eng. Process., 2007, 46, 165-174.

13 Y. U. Paulechka, A. G. Kabo, A. V. Blokhin, G. J. Kabo and M. P. Shevelyova, J. Chem. Eng. Data, 2010, 55, 2719-2724.

14 M. Ahrenberg, M. Brinckmann, J. W. P. Schmelzer, M. Beck, C. Schmidt, O. Keßler, U. Kragl, S. P. Verevkin and C. Schick, Phys. Chem. Chem. Phys., 2014, 16, 2971-2980.

15 U. Holzgrabe, B. W. K. Diehl and I. Wawer, J. Pharm. Biomed. Anal., 1998, 17, 557-616.

16 H.-J. Liaw, S.-K. Huang, H.-Y. Chen and S.-N. Liu, Green Chem., 2012, 14, 2001-2008. 